\title{
Bariatric surgery in individuals with liver cirrhosis: A narrative review
}

\author{
Everton Cazzo ${ }^{1 *}$, Martinho Antonio Gestic ${ }^{2}$, Murillo Pimentel Utrini³ ${ }^{3}$ Felipe David Mendonça Chaim², \\ Francisco Callejas-Neto ${ }^{4}$, José Carlos Pareja ${ }^{5}$, Elinton Adami Chaim ${ }^{6}$ \\ ${ }^{1} \mathrm{MD}$, PhD, Assistant Lecturer, Department of Surgery, Faculdade de Ciências Médicas, Universidade Estadual de Campinas (Unicamp), Campinas, SP, Brazil \\ ${ }^{2}$ MD, MSc, Assistant Lecturer, Department of Surgery, Faculdade de Ciências Médicas, Unicamp, Campinas, SP, Brazil \\ ${ }^{3} \mathrm{MD}$, Assistant Lecturer, Department of Surgery, Faculdade de Ciências Médicas, Unicamp, Campinas, SP, Brazil \\ ${ }^{4} \mathrm{MD}, \mathrm{MSc}$, Associate Professor, Department of Surgery, Faculdade de Ciências Médicas, Unicamp, Campinas, SP, Brazil \\ ${ }^{5} \mathrm{MD}$, PhD, Associate Professor, Department of Surgery, Faculdade de Ciências Médicas, Unicamp, Campinas, SP, Brazi \\ ${ }^{6} \mathrm{MD}$, PhD, Full Professor, Department of Surgery, Faculdade de Ciências Médicas, Unicamp, Campinas, SP, Brazil
}

Study conducted at Department of Surgery, Faculdade de Ciências Médicas,

Universidade Estadual de Campinas (Unicamp), Campinas, SP, Brazil

Article received: 6/23/2016 Accepted for publication: 6/26/2016

*Correspondence:

Departamento de Cirurgia, Unicamp

Address: R. Alexander Fleming, $\mathrm{s} / \mathrm{n}$ Campinas, SP - Brazi Postal code: $13083-887$ notrevezzo@yahoo.com.br

http://dx.doi.org/10.1590/1806-9282.63.02.190

\section{SUMMARY}

Introduction: Bariatric surgery has become the gold standard treatment for morbid obesity, but there is no consensus regarding its safety and efficacy among individuals with chronic liver diseases.

Objective: To critically evaluate the existing evidence on literature about bariatric surgery in individuals with liver cirrhosis.

Method: Narrative review performed by means of an online search in the MEDLINE and LILACS databases.

Results: Bariatric surgery is safe and effective in individuals with chronic liver disease without clinical decompensation or significant portal hypertension. Individuals with severe liver function impairment present significantly higher surgical morbidity and mortality. Among candidates to liver transplantation, surgery may be performed before, after and even during transplantation, and there is a predominant trend to perform it after. Vertical sleeve gastrectomy seems to be the most adequate technique in this group of subjects.

Conclusion: Bariatric surgery is safe and effective in individuals with compensated cirrhosis without significant portal hypertension, but presents higher morbidity. Among candidates to liver transplantation and/or individuals with severe portal hypertension, morbidity and mortality are significantly higher.

Keywords: liver diseases, obesity, bariatric surgery, liver cirrhosis, liver transplantation.

\section{INTRODUCTION}

Since the second half of the $20^{\text {th }}$ century, the world has seen a significant increase in the prevalence of overweight and obesity. According to the World Health Organization (WHO), there are more than 1.4 billion adults over their ideal weight, including more than 200 million men and almost 300 million women that are obese. Currently, $65 \%$ of the world's population lives in countries where obesity and overweight are responsible for more deaths than malnutrition. ${ }^{1}$

Likewise, the prevalence of obesity among cirrhotic individuals who are candidates for liver transplantation has almost doubled since the 1990s, reaching more than $30 \%{ }^{2,3}$ Furthermore, obesity and metabolic syndrome have presented an increasingly significant causal relationship with chronic liver disease. ${ }^{4}$ Non-alcoholic fatty liver disease (NAFLD) is currently the third leading cause of liver transplantation in the United States of America (USA). Also, there is evidence that, if suitable diagnostic criteria are applied, about $2 / 3$ of cases characterized as cryptogenic cirrhosis are actually caused by NAFLD. ${ }^{5,6}$ It is predicted that in 2030, NAFLD will be the leading cause of liver transplantation in the USA.?

In recent years, bariatric surgery has become the gold standard treatment for morbid obesity, leading to better results compared to clinical treatment. ${ }^{8}$ However, among obese patients with chronic liver disease, there is no consensus regarding the most effective and safest therapeutic 
strategy. The association between obesity and cirrhosis is a complex situation for various reasons. Encouraging the adoption of lifestyle changes in individuals with severe liver diseases is difficult, and bariatric surgeries present greater risks, with less favorable rates of morbidity and mortality. In addition to the isolated risk of liver disease, in patients with NAFLD and obesity, the existence of other comorbidities, such as atherosclerotic cardiovascular disease, diabetes, hypertension, dyslipidemia, metabolic syndrome and chronic nephropathy, is common. ${ }^{9}$ Given that the intersection between obesity and NAFLD is increasingly common, a deeper understanding of these interconnections and the possibilities of more suitable and safer management for the proper treatment of both conditions is necessary.

\section{Objective}

To conduct a critical analysis of the existing literature on the realization of bariatric surgery on patients with liver cirrhosis.

\section{Method}

A narrative review of the literature was conducted via an online search of the MEDLINE (via Pubmed) and LILACS (via Bireme) databases, using as keywords "bariatric surgery," "liver diseases" and "liver cirrhosis." The articles were located and reviewed, with an emphasis on those reporting on the results of bariatric surgical techniques in individuals with cirrhosis and/or chronic liver diseases.

\section{Results and Discussion}

In subjects with mild to moderate liver disease without cirrhosis, several studies have demonstrated the occurrence of regression of NAFLD after bariatric surgery, including individuals with significant fibrosis. ${ }^{10,11}$ This improvement occurs not only due to weight loss, but is also related to complex mechanisms linked to the structural and biochemical changes caused by the surgery, such as improved insulin sensitivity, increased incretin and adipokine activity, reduction of chronic inflammation and decreased lipid supply in the portal system. ${ }^{12}$

The main risk factors for postoperative impairment after performing bariatric surgery in chronic liver diseases are portal hypertension and hepatocytic insufficiency. In relation to severe cirrhotic liver transplant candidates, the choice of the most appropriate surgical technique and the time for completion of the surgery are relevant aspects that have not been completely established, especially due to the scarce literature on these topics.

In patients with severe cirrhosis, perioperative morbidity and mortality are higher than those observed in the obese population. Takata et al. ${ }^{13}$ assessed 15 patients with severe liver disease (six of which were cirrhotic patients) treated with vertical sleeve gastrectomy and noted a $33 \%$ loss of excess weight after one year, with perioperative complications in two (13.3\%) patients, both of whom were cirrhotic. In 26 transplant candidates submitted to vertical sleeve gastrectomy assessed by Lin et al., ${ }^{14}$ perioperative complications were noted in $23.1 \%$, with no mortality. The average loss of excess weight after one year was $50 \%$ and seven patients were submitted to transplant, without complications related to the bariatric surgery.

In a retrospective study based on a database analysis at the national level in the USA, Mosko et al. ${ }^{15}$ noted higher mortalities in clinically compensated $(0.9 \%)$ and non-compensated cirrhotic patients $(16.3 \%)$ when compared to individuals free of liver disease (0.3\%). Furthermore, in centers with a low volume of bariatric surgery, mortality reached $41 \%$ among individuals with decompensated cirrhosis.

Incidental diagnosis of liver cirrhosis in the intraoperative period of bariatric surgery is not rare, and is reported in 1 to $4 \%$ of cases. ${ }^{16,17}$ Dallal et al. ${ }^{18}$ analyzed a sample in which $90 \%$ of patients with cirrhosis had been diagnosed incidentally in the intraoperative period of the bariatric intervention and noted that among individuals with compensated cirrhosis (Child-Pugh A), the Roux-en-Y gastric bypass had a mortality rate similar to the general population, but with more episodes of transient renal dysfunction, greater surgery time and more bleeding and the need for blood products. Woodford et al. ${ }^{19}$ studied 14 patients with intraoperative diagnosis of cirrhosis during placement of an adjustable gastric band, without changes in hepatocyte function or portal hypertension, and did not note significant mortality or morbidity. Pestana et al. ${ }^{20}$ conducted a retrospective study comparing patients with Child-Pugh A cirrhosis and without portal hypertension, noting similar morbidity and mortality and considering surgery as being well-tolerated and safe therapeutic option in patients with compensated liver diseases and mild portal hypertension.

In a systematic review, Lazzati et al. ${ }^{21}$ found a $66 \%$ loss of excess weight within two years, comparable to that found in the general population. Vertical sleeve gastrectomy was the procedure conducted the most, and perioperative mortality was similar to that in the general population. However, the morbidity rate, in particular the frequency of reoperations, and the mortality rate in the first year were higher. The heterogeneity of the studies and the small number of individuals analyzed, even after the compilation of data, have been identified as 
factors that generate potential biases and limit the findings. Another systematic review, conducted by Jan et al., ${ }^{22}$ showed favorable results comparable to those of the general obese population in relation to weight loss and the resolution of comorbidities. On the other hand, the authors underscore that the risks are significantly higher, with $21.3 \%$ surgical morbidity, $1.6 \%$ perioperative mortality and $2.4 \%$ late-onset mortality. The risk of decompensation of liver function was also high (6.5\%) and should be taken into consideration. The main results of the studies evaluated are presented in Table 1.

Among severe cirrhotic patients that are candidate to liver transplant, the choice of technique to be employed is fundamental due to two key issues: potential damage to the absorption of immunosuppressive medication and the possibility of endoscopic access to the biliary tree. There are no studies examining the pharmacokinetics of immunosuppressants in liver transplant patients undergoing bariatric surgery. In kidney transplant patients undergoing gastric bypass, however, there are reports of a need for larger doses of tacrolimus, sirolimus, mycophenolate sodium and cyclosporine. ${ }^{23}$ With regard to access to the biliary tree, stenoses are common after deceased donor transplants, occurring in up to $17 \%$ of cases. ${ }^{24}$ Due to these factors, vertical sleeve gastrectomy appears to be the most appropriate technique in this group of patients, as it does not cause significant malabsorption and enables endoscopic access to the biliary tree.

The ideal time for bariatric surgery in liver transplant candidates is another controversial issue. There is a pos- sibility of performing the procedure before, after and even during transplantation. A relevant concern in this regard is the impact of obesity on the outcome of the transplant. Recent studies have reported that operative mortality, two-year survival and graft viability are similar in obese and non-obese individuals. Perioperative morbidity is slightly higher. ${ }^{2,3}$ Performing bariatric surgery in non-compensated transplant candidates leads to higher morbidity and mortality, including the occurrence of anastomotic fistulas, which often reaches $12.5 \%{ }^{21,22}$

Recently, there has been growing interest in the possibility of endoluminal treatments for obesity in individuals with high surgical risk. An endoscopic intragastric balloon implant in this group of patients, which is an attractive alternative, has presented satisfactory results in studies conducted by Choudhary et al. ${ }^{25}$

A case report by Campsen et al. ${ }^{26}$ showed the realization of adjustable gastric band implantation during a liver transplant had satisfactory results after 6 months. Heimbach et al. ${ }^{27}$ reported the combined realization of liver transplantation and vertical sleeve gastrectomy in seven patients with one case of a fistula on the staple line and zero mortality. The combined option is interesting because it reduces the number of surgical approaches in high-risk patients. On the other hand, this approach requires complex logistics (especially the concomitant availability of transplant and bariatric teams) and can combine serious complications that are not related to either procedure. ${ }^{21,22,26,27}$ Therefore, in patients with non-compensated cirrhosis or with moderate to severe portal hyper-

TABLE 1 Main results of bariatric surgery in individuals with liver diseases.

\begin{tabular}{|c|c|c|c|c|c|c|}
\hline Study & $\mathbf{N}$ & Type of study & Surgical technique & Morbidity & $\begin{array}{l}\text { Perioperative } \\
\text { mortality }\end{array}$ & Late mortality \\
\hline Takata et al. ${ }^{13}$ & 15 & Retrospective cohort & $\begin{array}{l}\text { Vertical sleeve gastrectomy } \\
\text { and gastric bypass }\end{array}$ & $13.3 \%$ & 0 & 0 \\
\hline Lin et al. ${ }^{14}$ & 26 & Retrospective cohort & Vertical sleeve gastrectomy & $23.1 \%$ & 0 & 0 \\
\hline $\begin{array}{l}\text { Mosko et al. }{ }^{15} \\
\text { (Compensated cirrhosis) }\end{array}$ & 3,888 & Retrospective cohort & Several & NR & $0.9 \%$ & NR \\
\hline $\begin{array}{l}\text { Mosko et al. }{ }^{15} \\
\text { (Decompensated cirrhosis) }\end{array}$ & 62 & Retrospective cohort & Several & NR & $16.3 \%$ & NR \\
\hline Dallal et al. ${ }^{18}$ & 30 & Retrospective cohort & Gastric bypass & $30 \%$ & 0 & $3.3 \%$ \\
\hline Woodford et al. ${ }^{19}$ & 14 & $\begin{array}{l}\text { Prospectively collected } \\
\text { database analysis }\end{array}$ & Adjustable gastric band & $14.3 \%$ & 0 & 0 \\
\hline Shimizu et al. ${ }^{31}$ & 23 & $\begin{array}{l}\text { Prospective database } \\
\text { analysis }\end{array}$ & $\begin{array}{l}\text { Vertical sleeve gastrectomy } \\
\text { and gastric bypass }\end{array}$ & $34.8 \%$ & 0 & $4.3 \%$ \\
\hline Lazzati et al. ${ }^{21}$ & 56 & Meta-analysis & Several & $23.2 \%$ & 0 & $5.3 \%$ \\
\hline Jan et al..$^{22}$ & 122 & Meta-analysis & Several & $21.3 \%$ & $1.6 \%$ & NR \\
\hline
\end{tabular}

$\mathrm{N}$ : number of patients; NR: not reported. 
tension, conducting the liver transplantation first and bariatric surgery a posteriori is preferred. The clearest advantage of this option is the selection of patients who have had a favorable outcome after transplantation and developed or maintained obesity, now with improvements in hepatocyte function and portal hypertension. Morbidity is higher than in the general population (reoperation rate of up to $33 \%$ ) but mortality is similar. ${ }^{21,22,28-30}$

\section{Conclusion}

In individuals with liver disease and preserved hepatocytic function and without significant portal hypertension, bariatric surgery is an effective and safe therapeutic option, with results close to those of patients without liver disease. In these cases, the techniques used the most are vertical sleeve gastrectomy and Roux-en-Y gastric bypass. In patients with severe liver diseases, candidates for transplantation or post-transplant patients, the most appropriate technique is vertical sleeve gastrectomy. Performing surgery prior to transplantation is significantly worse than in the general population and should be avoided. Considering the current encouraging results of liver transplantation in obese patients, the post-transplant approach seems to be the most appropriate. The realization of prospective controlled studies with large samples is required so that we can obtain more definitive conclusions.

\section{Conflict of interest}

The authors declare no conflict of interest.

\section{Resumo}

Cirurgia bariátrica em indivíduos com cirrose hepática: uma revisão narrativa

Introdução: A cirurgia bariátrica tornou-se nos últimos anos o tratamento padrão-ouro para a obesidade mórbida; porém, entre obesos portadores de hepatopatia crônica, não existe consenso a respeito de sua segurança e efetividade.

Objetivo: Análise crítica da literatura existente sobre a realização de cirurgia bariátrica em portadores de cirrose hepática.

Método: Revisão narrativa por meio de pesquisa online nas bases de dados Medline e Lilacs.

Resultados: As cirurgias bariátricas em indivíduos cirróticos sem descompensação clínica levam a resultados satisfatórios. Já indivíduos com hepatopatia grave apresentam morbidade perioperatória e mortalidade significativamente maiores do que as observadas na população obesa sem hepatopatia. Em candidatos a transplante hepático, a ci- rurgia pode ser realizada antes, durante ou após o transplante, havendo uma tendência predominante à realização após o transplante. A gastrectomia vertical parece ser a técnica mais adequada nesse grupo de pacientes.

Conclusão: A cirurgia bariátrica é segura e efetiva em portadores de cirrose hepática compensada e sem hipertensão portal; porém, apresenta maior morbidade. Em candidatos a transplante e/ou indivíduos com hipertensão portal significativa, a morbimortalidade é significativamente maior.

Palavras-chave: hepatopatias, obesidade, cirurgia bariátrica, cirrose hepática, transplante de fígado.

\section{References}

1. World Health Organization. World Health Statistics 2011. Geneva: WHO; 2011

2. Perez-Protto SE, Quintini C, Reynolds LF, You J, Cywinski JB, Sessler DI, et al. Comparable graft and patient survival in lean and obese liver transplant recipients. Liver Transpl. 2013; 19(8):907-15.

3. Singhal A, Wilson GC, Wima K, Quillin RC, Cuffy M, Anwar N, et al. Impact of recipient morbid obesity on outcomes after liver transplantation. Transpl Int. $2015 ; 28(2): 148-55$.

4. Cazzo E, de Felice Gallo F, Pareja JC, Chaim EA. Nonalcoholic fatty liver disease in morbidly obese subjects: correlation among histopathologic findings, biochemical features, and ultrasound evaluation. Obes Surg. 2014; 24(4):666-8

5. Shaker M, Tabbaa A, Albeldawi M, Alkhouri N. Liver transplantation for nonalcoholic fatty liver disease: new challenges and new opportunities. World J Gastroenterol. 2014; 20(18):5320-30.

6. Baran B, Akyüz F. Non-alcoholic fatty liver disease: what has changed in the treatment since the beginning? World J Gastroenterol. 2014; 20(39):14219-29.

7. Santos LF, Hernández G, Puerta AV, Beltrán O, Botero RC, Mejía G. Non alcoholic fatty liver disease: the new millennium Pandemia. Rev Col Gastroenterol. 2010; 25(4):373-91.

8. Buchwald H, Oien DM. Metabolic/bariatric surgery worldwide 2011. Obes Surg. 2013; 23(4):427-36.

9. Kumar N, Choudhary NS. Treating morbid obesity in cirrhosis: a quest of holy grail. World J Hepatol. 2015; 7(28):2819-28.

10. Moretto M, Kupski C, da Silva VD, Padoin AV, Mottin CC. Effect of bariatric surgery on liver fibrosis. Obes Surg. 2012; 22(7):1044-9.

11. Mummadi RR, Kasturi KS, Chennareddygari S, Sood GK. Effect of bariatric surgery on nonalcoholic fatty liver disease: systematic review and meta-analysis. Clin Gastroenterol Hepatol. 2008; 6(12):1396-402.

12. Cazzo E, Gestic MA, Utrini MP, Machado RR, Geloneze B, Pareja JC, et al Impact of Roux-en-Y gastric bypass on metabolic syndrome and insulin resistance parameters. Diabetes Technol Ther. 2014; 16(4):262-5.

13. Takata MC, Campos GM, Ciovica R, Rabl C, Rogers SJ, Cello JP, et al. Laparoscopic bariatric surgery improves candidacy in morbidly obese patients awaiting transplantation. Surg Obes Relat Dis. 2008; 4(2):159-64.

14. Lin MY, Tavakol MM, Sarin A, Amirkiai SM, Rogers SJ, Carter JT, et al Laparoscopic sleeve gastrectomy is safe and efficacious for pretransplant candidates. Surg Obes Relat Dis. 2013; 9(5):653-8.

15. Mosko JD, Nguyen GC. Increased perioperative mortality following bariatric surgery among patients with cirrhosis. Clin Gastroenterol Hepatol. 2011; 9(10):897-901

16. Silverman JF, O'Brien KF, Long S, Leggett N, Khazanie PG, Pories WJ, et al Liver pathology in morbidly obese patients with and without diabetes. Am J Gastroenterol. 1990; 85(10):1349-55.

17. Brolin RE, Bradley LJ, Taliwal RV. Unsuspected cirrhosis discovered during elective obesity operations. Arch Surg. 1998; 133(1):84-8.

18. Dallal RM, Mattar SG, Lord JL, Watson AR, Cottam DR, Eid GM, et al. Results of laparoscopic gastric bypass in patients with cirrhosis. Obes Surg. 2004; 14(1):47-53. 
19. Woodford RM, Burton PR, O’Brien PE, Laurie C, Brown WA. Laparoscopic adjustable gastric banding in patients with unexpected cirrhosis: safety and outcomes. Obes Surg. 2015; 25(10):1858-62.

20. Pestana L, Swain J, Dierkhising R, Kendrick ML, Kamath PS, Watt KD. Bariatric surgery in patients with cirrhosis with and without portal hypertension: a single-center experience. Mayo Clin Proc. 2015; 90(2):209-15.

21. Lazzati A, Iannelli A, Schneck AS, Nelson AC, Katsahian S, Gugenheim J, et al. Bariatric surgery and liver transplantation: a systematic review a new frontier for bariatric surgery. Obes Surg. 2015; 25(1):134-42.

22. Jan A, Narwaria M, Mahawar KK. A systematic review of bariatric surgery in patients with liver cirrhosis. Obes Surg. 2015; 25(8):1518-26.

23. Alexander JW, Goodman H. Gastric bypass in chronic renal failure and renal transplant. Nutr Clin Pract. 2007; 22(1):16-21.

24. Duailibi DF, Ribeiro MA Jr. Biliary complications following deceased and living donor liver transplantation: a review. Transplant Proc. 2010; 42(2):517-20.

25. Choudhary NS, Puri R, Saraf N, Saigal S, Kumar N, Rai R, et al. Intragastric balloon as a novel modality for weight loss in patients with cirrhosis and morbid obesity awaiting liver transplantation. Indian J Gastroenterol 2016; 35(2):113-6.
26. Campsen J, Zimmerman M, Shoen J, Wachs M, Bak T, Mandell MS, et al. Adjustable gastric banding in a morbidly obese patient during liver transplantation. Obes Surg. 2008; 18(12):1625-7.

27. Heimbach JK, Watt KDS, Poterucha JJ, Ziller NF, Cecco SD, Charlton MR, et al. Combined liver transplantation and gastric sleeve resection for patients with medically complicated obesity and end-stage liver disease. Am J Transplant. 2013; 13(2):363-8.

28. Butte JM, Devaud N, Jarufe NP, Boza C, Pérez G, Torres J, et al. Sleeve gastrectomy as treatment for severe obesity after orthotopic liver transplantation. Obes Surg. 2007; 17(11):1517-9.

29. Elli EF, Masrur MA, Giulianotti PC. Robotic sleeve gastrectomy after liver transplantation. Surg Obes Relat Dis. 2013; 9(1):e20-2.

30. Pajecki D, Cesconetto DM, Macacari R, Joaquim H, Andraus W, de Cleva R, et al. Bariatric surgery (sleeve gastrectomy) after liver transplantation: case report. Arq Bras Cir Dig. 2014; 27(Suppl 1):81-3.

31. Shimizu H, Phuong V, Maia M, Kroh M, Chand B, Schauer PR et al. Bariatric surgery in patients with liver cirrhosis. Surg Obes Relat Dis. 2013;9(1):1-6. 